\title{
The metabolomics of psoriatic disease
}

\author{
This article was published in the following Dove Press journal: \\ Psoriasis: Targets and Therapy \\ 31 January 2017 \\ Number of times this article has been viewed
}

\section{Di Yan \\ Ladan Afifi \\ Caleb Jeon \\ Megha Trivedi \\ Hsin Wen Chang \\ Kristina Lee \\ Wilson Liao \\ Department of Dermatology, University of California-San Francisco, San Francisco, CA, USA}

Correspondence: Di Yan

Department of Dermatology, University of California-San Francisco, 2340 Sutter Street, San Francisco, CA 94II5, USA

Tel +l 2673033932

Email Di.Yan@ucsf.edu

\begin{abstract}
Metabolomics is an emerging new "omics" field involving the systematic analysis of the metabolites in a biologic system. These metabolites provide a molecular snapshot of cellular activity and are thus important for understanding the functional changes in metabolic pathways that drive disease. Recently, metabolomics has been used to study the local and systemic metabolic changes in psoriasis and its cardiometabolic comorbidities. Such studies have revealed novel insights into disease pathogenesis and suggest new biochemical signatures that may be used as a marker of psoriatic disease. This review will discuss common strategies in metabolomics analysis, current findings in the metabolomics of psoriasis, and emerging trends in psoriatic metabolomics.
\end{abstract}

Keywords: metabolome, psoriasis, psoriatic arthritis, skin, urine, metabolites

\section{Introduction}

Metabolites are the small molecules that serve as the substrates, intermediates, and products of cellular pathways. Collectively, the full spectrum of metabolites in a biologic system forms the metabolome, which represents the ultimate culmination of gene expression, epigenetics, protein activity, and environmental influences. As such, metabolites are a direct, functional reflection of the biochemical processes occurring in a particular phenotype. The study of metabolites has long been integral to our understanding of human health and disease. The importance of metabolites in medicine was first noted by Chinese and Hindu practitioners in the 15th century BC who observed that the presence of a sweet compound in urine was associated with the disease now known as diabetes. Modern methods of metabolite analysis were pioneered thousands of years later in 1971 by Linus Pauling, who used gas chromatography (GC) to analyze the composition of breath and urine vapor. ${ }^{1}$ Despite the history of metabolites in medicine, the term "metabolomics" was not formally coined until 1998, when researchers led by Oliver et $\mathrm{al}^{2}$ and Tweeddale et $\mathrm{al}^{3}$ separately described the emergence of a new "omics" field dedicated to the systematic identification and quantification of the metabolome.

Since then, the role of modern metabolomics in medical research has continued to evolve and the metabolome has been increasingly recognized as an essential aspect of our understanding of human disease. The profound relationship between health and the metabolome is driven by the ability of small shifts in biochemical pathways to produce dramatic changes in cellular metabolites. In disorders with clear metabolic causes, such as diabetes and heart disease, metabolomics has provided key insights into disease pathogenesis. ${ }^{4-6}$ Yet, even when metabolic derangements do not overtly 
drive the disease process, the effects of disease can still provoke insightful alterations in the metabolome. For instance, inflammatory conditions, ${ }^{7-9}$ neurodegenerative disease, ${ }^{10}$ infections, ${ }^{11,12}$ and cancer ${ }^{13-15}$ can all fundamentally change cellular metabolism, allowing for the identification of novel biomarkers that aid in the prediction, diagnosis, and understanding of disease. More recently, metabolomics has been applied to dermatology, where it has been used to identify characteristic biomarker profiles in metastatic melanoma, ${ }^{16,17}$ basal cell carcinoma, ${ }^{18}$ acute intermittent porphyria, ${ }^{19}$ and atopic dermatitis. ${ }^{20}$

However, one of the most promising areas of skin research has been the application of metabolomics to the study of psoriatic disease. Several features of psoriasis suggest that it has metabolic underpinnings important to disease pathogenesis, outcomes, and treatment. Most interestingly, psoriasis is strongly associated with various cardiometabolic comorbidities including atherosclerosis, diabetes, and obesity. Metabolomic studies of these psoriatic comorbities have revealed heightened activity of inflammatory pathways ${ }^{21,22}$ and a previously unappreciated pathogenic role of metabolites derived from the gut microbiome. ${ }^{6,23,24}$ Metabolomics is, therefore, an ideal approach for investigating the link between psoriasis, cardiometabolic comorbidities, and the microbiome. Furthermore, unlike genomics and proteomics, metabolomics can capture the downstream effects of environmental factors, such as diet on psoriasis. This review will provide an overview of common analytic strategies used in metabolomics, summarize the findings of metabolomic studies in psoriasis, and discuss emerging trends in psoriasis metabolomics.

\section{Materials and methods}

We conducted a systematic review of the literature in PubMed and Embase using the Medical Subject Headings terms provided in Table S1. References from the assembled articles were also reviewed. We included only published articles from peer-reviewed journals. This search strategy yielded 126 PubMed and 141 Embase abstracts, which were then evaluated by the study team members based on predetermined exclusion and inclusion criteria: 1) study involved subjects with either psoriasis or psoriatic arthritis and 2) study quantified endogenous metabolites in human subjects. We excluded case reports, in vitro or ex vivo experiments, methodology papers, redundant studies, and pharmacokinetic or toxicity studies that looked exclusively at the metabolism of specific drug or xenobiotic substance. Thirty-eight abstracts were selected for review, full-text articles could not be found for
2 potentially qualifying abstracts, and 16 articles met all criteria (Tables 3-5).

\section{Approaches and techniques}

Studies of the metabolome can be broadly divided into targeted and untargeted approaches. Targeted metabolomics involves the analysis of a prespecified set of metabolites, often related to a particular pathway or network of pathways of interest. Metabolomic studies can also be untargeted, that is, they aim to generate a global picture of metabolic activity without focusing on particular metabolites that have been defined a priori. One type of approach in untargeted metabolomics is metabolic fingerprinting, which uses a pattern of metabolite composition to categorize or identify samples. Another untargeted approach is metabolite profiling, which refers to the simultaneous measurement of as many metabolites as possible to produce a comprehensive "snapshot" of metabolic activity in a biologic system. The data generated by untargeted metabolomics are very complex and high volume, typically requiring processing with specialized bioinformatics software, such as various forms $(\mathrm{X})$ of chromatography mass spectrometry ${ }^{25}$ and comparison to metabolite databases, such as METLIN ${ }^{26}$ and the Human Metabolome Database. ${ }^{27}$ To interpret the processed data in a meaningful way, it must then be mapped onto metabolic pathway databases, such as the Kyoto Encyclopedia of Genes and Genomes. ${ }^{28}$ This requires sophisticated statistical tools, such as MetaboAnalyst ${ }^{29}$ and MetaMapR, ${ }^{30}$ to perform pathway and network analyses.

Sample analysis involves the separation of the mixture into its biochemical constituents followed by the identification and quantification of each component. The most commonly used instruments for identification and quantification in the study of metabolomics are mass spectrometry (MS) and nuclear magnetic resonance (NMR) spectroscopy. Each analytical platform has distinct advantages and limitations (Table 1). MS ionizes analytes and separates the ions based on mass to charge ratio. Although samples can be directly injected into a mass spectrometer, MS-based analysis is usually coupled to a variety of analyte separation techniques, which can influence the accuracy and sensitivity of MS-based methods (Table 2). These separation methods include GC, capillary electrophoresis (CE), and liquid chromatography (LC) and its variations, such as high performance liquid chromatography (HPLC) and ultra-high performance liquid chromatography (UPLC).

Although ideal for volatile and thermally stable compounds, GC requires that the nonvolatile constituents of a sample be chemically derivatized to a volatile form for 
Table I Comparison of NMR and MS based platforms for metabolite analysis

\begin{tabular}{lll}
\hline Sample & NMR & MS \\
\hline Recovery & Preservation of sample & Sample destroyed \\
Separation & Not needed-simultaneously separates and identifies & Usually needs to be coupled to separation technique \\
Derivatization & Not needed & Yes, if separating by GC \\
Volume & Large $(0.1-0.5 \mathrm{~mL})$ & Small-Moderate (I0-I00 $\mu$ L) \\
Sensitivity & Lower (LOD $0.5 \mu \mathrm{M})$ & Higher (LOD up to 0.5 nM with LC-MS) \\
Selectivity & Mostly nonselective analysis & Selective and nonselective analysis \\
Identification of unknowns & More structural information, better identification & Difficult to identify new metabolites \\
Detection range & of unknowns & $500+$ metabolites simultaneously \\
Analysis time & $40-200$ metabolites simultaneously & Slow (I5-40 minutes/sample) \\
In vivo & Fast (2-3 minutes/sample) & No, requires sample extraction \\
Reproducibility & Can be used in vivo & Moderate \\
\hline
\end{tabular}

Note: Data obtained from various review studies. , $^{31,33,36}$

Abbreviations: GC, gas chromatography; LC, liquid chromatography; LOD, limit of detection; MS, mass spectrometry; NMR, nuclear magnetic resonance.

Table 2 Comparison of separation methods compatible with mass spectrometry

\begin{tabular}{llll}
\hline Sample & Gas chromatography & Capillary electrophoresis & Liquid chromatography \\
\hline Derivatization & Yes for nonvolatiles & No & No \\
Min volume requirement & Moderate $(I \mu \mathrm{L})$ & Small $(\mathrm{I}-20 \mathrm{~nL})$ & Moderate $(\mathrm{I5} \mu \mathrm{L})$ \\
Type & No solids, only volatile compounds & Liquid only & No gas, solids must be solubilized \\
Analyte range & Nonpolar and slightly polar & Charged and polar & Polar and nonpolar \\
Data interpretation & Established libraries for comparison & Newer technology, many unknowns & Newer technology, many unknowns \\
\hline
\end{tabular}

Note: Data obtained from various review studies. ${ }^{31-35}$

Abbreviation: min, minimum.

injection into the gas phase. ${ }^{31}$ Components of the sample mixture are then separated based on volatility and size. ${ }^{32}$ Derivatization is a significant drawback to the GC separation method because it can render sample preparation excessively complex and expensive and introduce experimental artifacts (Table 2). ${ }^{31}$ Because analytes must be volatile, GC is not effective for separating large, highly polar, or charged compounds and cannot be used on solid samples. ${ }^{33}$ Other limitations of GC-MS include its interbatch variability and the time-consuming nature of its sample analysis (20-40 minutes per sample). ${ }^{31}$ Despite its drawbacks, of all the analytic methods discussed, GC-MS is the most mature technology with established fragmentation libraries for the identification of separated sample constituents.

In contrast to GC, LC-based methods perform the separation process in the liquid phase and do not require derivatization for biologic fluid samples. LC offers a far broader range of metabolite coverage than $\mathrm{GC}$, encompassing both polar and nonpolar compounds. ${ }^{32}$ Unlike GC, LC can process solid samples in addition to liquid samples. Modern LC-based techniques, such as HPLC and UPLC, can detect analytes present in concentrations $<5$ parts per billion. ${ }^{32}$ However, LC-based approaches are hampered by the lack of MS fragmentation libraries against which analytes can be compared and identified. ${ }^{31}$ Furthermore, GC, LC, and its variations are time-consuming, requiring $\sim 15-40$ minutes per sample. ${ }^{31} \mathrm{LC}-\mathrm{MS}$ also has limited quantification capabilities compared to NMR. ${ }^{31}$

A third option is CE, which separates sample components by charge and size. CE can thus only be used to separate charged and polar metabolites. However, compared to other separation techniques, $\mathrm{CE}$ is faster, requiring $<20$ minutes per sample and a significantly smaller sample volume (1-20 nL). ${ }^{32} \mathrm{CE}$ also offers higher resolution separation (plate numbers on the order of 100,000-1,000,000) ) $^{34,35}$ and can analyze a wider range of metabolites than GC.

In general, MS-based approaches offer higher sensitivity compared to NMR. Modern MS platforms can detect metabolite on the order of picomole to femtomole concentrations. ${ }^{33} \mathrm{MS}$ can also analyze a broader range of metabolites simultaneously, allowing for high throughput analyses of the metabolome. These advantages make MS-based methods more ideal for untargeted metabolomic analyses. However, MS-based analyses generate data that are less reproducible than NMR results and consume the sample, preventing repeat testing. Additionally, most MS techniques offer less detailed structural information than NMR, rendering novel metabolite identification difficult.

Unlike MS, NMR simultaneously separates, identifies, and quantifies sample components based on characteristic resonance patterns generated by individual constituents. Consequently, NMR does not require prior sample separation 
or derivatization. In general, NMR requires larger sample volumes $(0.1-0.5 \mathrm{~mL})$ is a less sensitive technique than MS and has a higher limit of detection $(5 \mu \mathrm{M}) .{ }^{36}$ As a result, NMR may miss low abundance metabolites. Another disadvantage of NMR is that it can only measure $\sim 40-200$ compounds simultaneously. ${ }^{36}$ This is considerably less than LC-MS, which can analyze over 500 species at a time. ${ }^{36}$ However, NMR can analyze solid and liquid samples and has the most unbiased coverage of metabolites, although it cannot detect or identify salts, inorganic ions, or nonprotonated compounds. ${ }^{31} \mathrm{~A}$ unique advantage of NMR is that it provides more structural information, facilitating the identification of new metabolites. Although NMR is more expensive, the data are more reproducible with faster sample processing times (2-3 minutes). ${ }^{31}$ In addition, NMR is nondestructive and can be done in vivo or in vitro, allowing for noninvasive analysis of living biologic systems. ${ }^{36}$

As new technological innovations arise, the analytic capabilities of NMR and MS-based methods have continued to expand and improve. Recently, the development of metabolite imaging has dramatically expanded the applications of metabolomics. For example, functional magnetic resonance imaging and magnetic resonance spectroscopic imaging use NMR-based technology to map metabolites in vivo, allowing for imaging of sensitive tissues, such as the neonatal brain. ${ }^{37}$ Similarly, desorption electrospray ionization has allowed for rapid, intraoperative mapping of oncometabolites to guide neurosurgical excisions of patient tumors. ${ }^{38}$ Molecular cartography has also used MS-based approaches to provide three dimension (3D) spatial localization of metabolite distributions on the surface of human skin. ${ }^{39}$ Other technologic developments have enhanced the ability of MS and NMR to characterize the structure of metabolites. The use of traditional proton NMR $\left({ }^{1} \mathrm{H}\right.$ NMR) in metabolomics can now be supplemented with carbon $13\left({ }^{13} \mathrm{C}\right.$ NMR), ${ }^{40}$ Phosphorus 31 ( ${ }^{31} \mathrm{P}$ NMR), ${ }^{41}$ and 2D NMR. ${ }^{40}$ Likewise, the application of tandem mass spectrometry (MS-MS) provides structural information in MS-based analyses. ${ }^{42}$ These innovations can facilitate the identification of unknown metabolites, which may serve as novel biomarkers of disease.

\section{Metabolomics in psoriasis and psoriatic arthritis}

Skin

Differences in metabolites within psoriatic skin lesions were identified in several of the studies comparing psoriatic lesions to symptom-free psoriatic and/or healthy control skin (Table 3). Among these metabolites, a few appear to be associated with supporting hyperproliferative or hypermetabolic states: glutamic acid, choline, valine, glucose, and myo-inositol. This parallels cancer metabolic profiles as both diseases are characterized by high cellular proliferation rates. ${ }^{43,44}$ Using NMR and MS techniques, two studies found an increase in glutamic acid and glutamic acid:serine ratio in psoriatic lesions compared to symptom-free psoriatic skin and healthy controls. ${ }^{45,46}$ This increase in glutamic acid may be secondary to an increased demand for glutamine during cellular hyperproliferation, rapid protein synthesis, and cytokine production-conditions that are commonly involved in the pathogenesis of psoriasis. ${ }^{47,48}$ Similarly, choline is a building block needed for cell growth and division and was found to be elevated in psoriatic lesional skin compared to symptom-free psoriatic skin and healthy controls in two studies using NMR and MS analysis. ${ }^{45,49}$ Moreover, both glutamic acid and choline were found to have a positive correlation with psoriasis severity based on the plaque severity scale, likely due to the increasing cellular proliferation and inflammation. ${ }^{45}$ Alternatively, decreased levels of glucose, myo-inositol, and valine-leucine/isoleucine ratios were found in psoriatic lesions compared to nonlesional psoriatic skin, which may be due to accelerated turnover of these metabolites in rapidly proliferating cells. Interestingly, a study measuring metabolites following use of glucocorticoid therapy observed changes in choline, glutamic acid, and glucose levels comparable to uninvolved psoriatic skin. ${ }^{49}$ This reduction in these metabolites needed for production highlights the antiproliferative effects of steroids. In addition, the anti-inflammatory effects of steroids are noted, as increased levels of choline in inflammatory processes have been observed. ${ }^{44}$

Several metabolites that are altered in psoriatic lesions are believed to be due to changes in the metabolic pathway secondary to inflammation. Phenylalanine was increased in psoriatic lesions compared to symptom-free psoriasis skin and healthy controls, but levels were not correlated with disease severity. ${ }^{45}$ Phenylalanine metabolism is interrupted by immune activity and, therefore, the metabolite accumulates. ${ }^{50}$ An increase in taurine and taurine:alanine ratio was associated with psoriatic lesions. ${ }^{46,49}$ Taurine is an abundant amino acid in leukocytes and is found in high concentrations in inflammatory lesions and tissues exposed to oxidative stress. ${ }^{51,52} \mathrm{~A}$ decrease in urocanic acid was observed in psoriatic lesions compared to uninvolved psoriatic skin and healthy control. ${ }^{45}$ Urocanic acid, which is predominantly found in the stratum corneum, has been implicated in immunomodulatory effects following ultraviolet light conversion to cis-urocanic 
Table 3 Metabolomics studies of psoriasis using skin samples

\begin{tabular}{|c|c|c|c|c|c|}
\hline Studies & Study objectives & Subjects & Techniques & Key results & Implications \\
\hline Sitter et $\mathrm{al}^{49}$ & $\begin{array}{l}\text { Explore the metabolic } \\
\text { pattern of uninvolved } \\
\text { skin, psoriatic lesional } \\
\text { skin and corticosteroid } \\
\text { treated psoriatic skin }\end{array}$ & $\begin{array}{l}\text { I0 plaque Ps } \\
\text { patients each } \\
\text { provided } 3 \\
\text { skin samples: } \\
\text { I) Ps lesion, } \\
\text { 2) uninvolved } \\
\text { skin, 3) Ps } \\
\text { lesion treated } \\
\text { with clobetasol } \\
\text { ointment }\end{array}$ & 'H NMR & $\begin{array}{l}\text { Ps lesion versus uninvolved: Increased } \\
\text { choline and taurine, decreased myo- } \\
\text { inositol, and glucose in lesion } \\
\text { In Ps lesion treated versus untreated: } \\
\text { Glycerophophocholine higher in treated } \\
\text { skin } \\
\text { Improvement versus no improvement } \\
\text { after treatment: Patients who improved } \\
\text { had higher glucose, myo-inositol, GPC } \\
\text { and glycine, and lower choline }\end{array}$ & $\begin{array}{l}\text { Metabolite changes similar } \\
\text { to findings in cancer } \\
\text { patients and may reflect } \\
\text { hyperproliferation } \\
\text { Metabolites in skin may be } \\
\text { used to monitor or predict } \\
\text { treatment response to } \\
\text { topical steroids }\end{array}$ \\
\hline $\begin{array}{l}\text { Dutkiewicz } \\
\text { et } \mathrm{al}^{45}\end{array}$ & $\begin{array}{l}\text { Determine differences } \\
\text { in skin metabolites in } \\
\text { Ps skin and how these } \\
\text { changes differ with } \\
\text { severity of plaques using } \\
\text { the PSS }\end{array}$ & $\begin{array}{l}\text { I00 Ps patients } \\
\text { ( } 2 \text { samples- } \\
\text { lesional and } \\
\text { uninvolved) } \\
100 \text { healthy } \\
\text { volunteers } \\
\text { matched } \\
\text { for race, } \\
\text { age, gender }\end{array}$ & MS & $\begin{array}{l}\text { Lesional Ps versus controls: Higher } \\
\text { choline, glutamic acid, phenylalanine and } \\
\text { lower lactic acid, urocanic acid, citrulline } \\
\text { in lesional Ps } \\
\text { Lesional versus nonlesional Ps: Higher } \\
\text { choline, glutamic acid, phenylalanine, and } \\
\text { lower lactic acid, urocanic acid, citrulline } \\
\text { in lesional Ps } \\
\text { Correlated with PSS: Choline, glutamic } \\
\text { acid positively correlated with severity } \\
\text { Urocanic acid, citrulline negatively } \\
\text { correlated }\end{array}$ & $\begin{array}{l}\text { Metabolic changes may } \\
\text { reflect hyperproliferation, } \\
\text { reduced immunomodulation, } \\
\text { and impairment of } \\
\text { phenylalanine metabolism by } \\
\text { inflammation }\end{array}$ \\
\hline Kim et al ${ }^{46}$ & $\begin{array}{l}\text { Determine whether } \\
\text { 'H NMR is sufficiently } \\
\text { sensitive to discern } \\
\text { differences between } \\
\text { normal and diseased } \\
\text { skin }\end{array}$ & $\begin{array}{l}6 \text { Ps patients } \\
\text { ( } 2 \text { samples- } \\
\text { Ps lesion and } \\
\text { uninvolved skin) } \\
6 \text { site matched } \\
\text { skin from } \\
\text { healthy controls }\end{array}$ & $\begin{array}{l}\text { 'H NMR, } \\
\text { confirmed with } \\
\text { GC-MS }\end{array}$ & $\begin{array}{l}\text { Glu:Ser, creatine:Gly, and taurine:Ala } \\
\text { were threefold greater in psoriatic } \\
\text { lesions compared with symptom free or } \\
\text { normal skin } \\
\text { Val:Leu/lle was one-half the normal skin }\end{array}$ & $\begin{array}{l}\text { Similar metabolite changes } \\
\text { are seen in melanoma and } \\
\text { may reflect hypermetabolic } \\
\text { or hyperproliferative state } \\
\text { Uninvolved areas of psoriasis } \\
\text { patients shared spectral } \\
\text { patterns in both psoriatic } \\
\text { plaque areas and healthy } \\
\text { control skin }\end{array}$ \\
\hline $\begin{array}{l}\text { Hammarström } \\
\text { et } \mathrm{al}^{62}\end{array}$ & $\begin{array}{l}\text { Compare levels of free } \\
\text { arachidonic acid, PGE2, } \\
\text { PGF2, and HETE in } \\
\text { uninvolved and involved } \\
\text { epidermis }\end{array}$ & $\begin{array}{l}\text { Uninvolved and } \\
\text { involved lesions } \\
\text { of psoriasis } \\
\text { patients }\end{array}$ & $\begin{array}{l}\text { MS with- } \\
\text { deuterium- } \\
\text { labeled carriers } \\
\text { and multiple } \\
\text { ion analysis }\end{array}$ & $\begin{array}{l}\text { Involved epidermis had greater } \\
\text { arachidonic acid, } 12 \text { HETE, PGE2, and } \\
\text { PGF2 } \alpha \text { compared to uninvolved skin } \\
\text { The arachidonic acid and } \\
\text { hydroxyeicosatetraenoic acid levels } \\
\text { in involved epidermis were strongly } \\
\text { correlated }\end{array}$ & $\begin{array}{l}\text { The increased levels } \\
\text { of arachidonic acid } \\
\text { and I2-HETE in } \\
\text { involved epidermis } \\
\text { may have diagnostic } \\
\text { and pathophysiological } \\
\text { importance }\end{array}$ \\
\hline Brain et al ${ }^{65}$ & $\begin{array}{l}\text { Determine whether } \\
\text { there are differences } \\
\text { in arachidonic acid } \\
\text { metabolites between } \\
\text { untreated lesional } \\
\text { psoriasis versus } \\
\text { uninvolved skin }\end{array}$ & $\begin{array}{l}\text { Il patients } \\
\text { with untreated } \\
\text { chronic plaque } \\
\text { Ps ( } 2 \text { samples: } \\
\text { lesional and } \\
\text { uninvolved skin) }\end{array}$ & HPLC & $\begin{array}{l}\text { Lesional skin had higher LTB4 and also } \\
\text { contained a biologically active mono- } \\
\text { HETE }\end{array}$ & $\begin{array}{l}\text { Arachidonic pathway } \\
\text { metabolites leukotriene } \\
\text { B4 and I2-HETE may play } \\
\text { role in the pathogenesis of } \\
\text { the neutrophilic infiltrate in } \\
\text { psoriasis }\end{array}$ \\
\hline Barr et $\mathrm{al}^{63}$ & $\begin{array}{l}\text { To determine whether } \\
\text { quantitative analysis } \\
\text { of several arachidonic } \\
\text { acid metabolites } \\
\text { within exudate } \\
\text { collections of abraded } \\
\text { skin differs between } \\
\text { involved psoriasis skin, } \\
\text { uninvolved psoriasis skin } \\
\text { and healthy control skin }\end{array}$ & $\begin{array}{l}5 \text { patients } \\
\text { with chronic } \\
\text { plaque psoriasis } \\
\text { ( } 4 \text { males, I } \\
\text { female) and } \\
7 \text { healthy } \\
\text { controls } \\
\text { ( } 6 \text { males and } \\
\text { I female) }\end{array}$ & GC-MS & $\begin{array}{l}\text { Involved Ps versus normal: Increased } \\
\text { arachidonic acid and I2-HETE in } \\
\text { involved Ps } \\
\text { Involved versus uninvolved Ps: Increased } \\
\text { arachidonic acid, I2-HETE in involved Ps } \\
\text { No significant differences between } \\
\text { healthy normal control and uninvolved } \\
\text { skin } \\
\text { No significant differences in PGE2 }\end{array}$ & $\begin{array}{l}\text { Supports a role of } \\
\text { lipoxygenase pathway } \\
\text { products in the pathogenesis } \\
\text { of psoriasis }\end{array}$ \\
\hline
\end{tabular}

Abbreviations: GC, gas chromatography; GPC, glycerophosphorylcholine; HETE, hydroxyeicosatetraenoic acid; 'H NMR, proton nuclear magnetic resonance; HPLC, high performance liquid chromatography; LTB4, leukotriene B4; MS, mass spectroscopy; PGE2, prostaglandin E2; PGF2, prostaglandin F2; Ps, psoriasis; PSS, plaque severity scale. 
acid, a natural killer cell activity suppressor. ${ }^{53}$ Urocanic acid has been shown to be negatively correlated with disease severity, ${ }^{45}$ possibly indicating a deficit of local immunosuppression by cis-urocanic acid. Other metabolite disturbances are likely due to disruption of normal epidermal structures and function. For example, a reduction in lactic acid is observed in psoriatic lesions compared to nonlesional psoriatic skin and healthy controls, which is most likely a result of altered metabolism in sweat glands and keratinocytes or an obstructed sweat duct. ${ }^{45,54}$ Citrulline was also found to be decreased in psoriatic skin and is generally found attached to proteins, which have been found to be reduced in the hyperproliferative epidermis and may explain the positive correlation with disease severity. ${ }^{45,55}$

While skin metabolomics have provided biochemical evidence of high cell turnover and immune dysregulation in psoriasis, they also offer possible mechanisms for keratinocyte hyperproliferation. Abeyakirthi et $\mathrm{al}^{56}$ used HPLC to analyze tape strip samples from healthy controls and patients with psoriasis. Their study demonstrated increased levels of epidermal ornithine and decreased levels of arginine in psoriatic lesions. These perturbations suggest overexpression of arginase 1, an enzyme that competes with inducible nitric oxide synthase (iNOS) for the shared substrate arginine. iNOS is responsible for producing high levels of NO, which is released from keratinocytes and inhibits cell proliferation, whereas promoting differentiation in vivo. ${ }^{57}$ Increased use of arginine by arginase 1, reduces its availability for iNOS, leading to low NO levels, which promotes epidermal hyperproliferation in psoriasis. ${ }^{58}$ Abeyakirthi et al found that treatment with an aqueous $\mathrm{NO}$ donor gel reduced psoriatic plaque severity by $65 \%$ compared to a control gel in psoriasis patients. ${ }^{56}$

Outside of the NOS pathway, arachidonic acid metabolites have been of interest as potential contributors to the pathogenesis of psoriasis and promising therapeutic targets. Arachidonic acid is a polyunsaturated omega- 6 fatty acid (PUFA) that can be oxidized to a variety of eicosanoids by cyclooxygenase 21, lipoxygenase 22 (LOX), and cytochrome P450 enzymes. ${ }^{59}$ In particular, the LOX pathways produce hydroxyeicosatetraenoic acids (HETEs) and leukotriene B4 (LTB4), a leukocyte chemoattractant, that is, thought to induce keratinocyte activation and neutrophil-mediated inflammation in psoriasis. ${ }^{60,61}$ Several skin-based metabolomics studies have found higher concentrations of arachidonic acid, ${ }^{62,63}$ HETEs, ${ }^{62,63}$ and LTB4 ${ }^{64,65}$ in lesional psoriatic skin, suggesting that a shift toward LOX-mediated leukotriene production in lesional skin may play a pathogenic role in psoriasis. Indeed, the consumption of fish oil or omega-3 PUFAs may modulate eiconsanoid production and has been found to moderately reduce psoriasis symptoms. ${ }^{66}$

In contrast to the systemic perspective offered by blood and urine samples, skin tissue offers the closest look at the disease process and the local changes caused by psoriasis. Although skin-based metabolomics are the most invasive approach, direct sampling of psoriatic lesions allows for the correlation of metabolomic data with lesion morphology and gene expression data from local inflammatory cells and keratinocytes. Skin-based metabolomics, therefore, has the greatest potential to elucidate the immune mechanisms that drive disease pathogenesis and identify novel therapeutic targets. Other applications of skin metabolomics in psoriasis include investigating the role of the skin microbiome in local immune modulation. More recent technologic innovations have enabled the possibility of combining skin metabolomics with in vivo NMR and metabolomic imaging to correlate metabolite changes with disease activity and tissue architecture. This approach has already been applied to prostate cancer, where it has demonstrated promise in visualizing biochemical changes during disease progression and evaluating cancer aggressiveness. ${ }^{67}$

\section{Blood}

The psoriatic metabolome has not only been studied at the level of the skin, but plasma sampling and chromatographic techniques have allowed for further exploration of systemic perturbations of metabolic processes (Table 4). Blood ratios and relative concentrations of key metabolites including amino acids, lipids, and fatty-acid derivatives have been assessed for their role in the pathogenesis, prognosis, and treatment of psoriasis and other autoimmune conditions.

Protein metabolites are often the final products of complex metabolic pathways and therefore are the most closely correlated with phenotypic manifestations of disease. Therefore, understanding the amino acid profiles of psoriasis patients can better inform the disease process. Understanding the pathogenesis of psoriasis at the molecular level has been an ongoing effort in the field of psoriasis research. For example, Armstrong et al analyzed metabolite differences in psoriasis, psoriatic arthritis, and healthy control sera to elucidate the pathogenic processes, such as keratinocyte hyperproliferation and immune overactivation that underlie psoriasis. ${ }^{47}$ Armstrong's study found that psoriasis patients exhibited lower overall levels of glutamine and asparagine compared to healthy controls. The authors suggested that glutamine, which plays 
Table 4 Metabolomics studies of psoriasis using blood samples

\begin{tabular}{|c|c|c|c|c|c|}
\hline Studies & Study objectives & Subjects & Techniques & Results & Implications \\
\hline $\begin{array}{l}\text { Armstrong } \\
\text { et } \mathrm{al}^{47}\end{array}$ & $\begin{array}{l}\text { Differences in metabolite } \\
\text { profiles among psoriasis } \\
\text { patients with and without } \\
\text { psoriatic arthritis and } \\
\text { healthy controls }\end{array}$ & $\begin{array}{l}\text { IO Ps only } \\
\text { IO Ps and PsA } \\
10 \text { healthy controls }\end{array}$ & GC-MS & $\begin{array}{l}\text { Ps versus control: Ps had } \\
\text { higher alpha ketoglutaric } \\
\text { acid, lower asparagine, lower } \\
\text { glutamine } \\
\text { Ps and PsA versus control: Ps } \\
\text { and PsA had higher glucuronic } \\
\text { acid } \\
\text { PsA versus Ps: PsA had lower } \\
\text { alpha ketoglutaric acid, higher } \\
\text { lignoceric acid }\end{array}$ & $\begin{array}{l}\text { Metabolite changes may } \\
\text { reflect hyperproliferation, } \\
\text { hyperfunctioning of immune } \\
\text { cells, and increased oxidative } \\
\text { stress } \\
\text { High glucuronic acid may be } \\
\text { due to joint involvement in PsA } \\
\text { Elevated lignoceric acid in } \\
\text { both Pso and Psa may reflect } \\
\text { systemic inflammation and } \\
\text { metabolic syndrome }\end{array}$ \\
\hline $\begin{array}{l}\text { Kamleh } \\
\text { et al }{ }^{69}\end{array}$ & $\begin{array}{l}\text { To determine the plasma } \\
\text { metabolite differences } \\
\text { in mild and severe } \\
\text { psoriasis compared to } \\
\text { healthy controls and the } \\
\text { effect of the anti-TNF } \alpha \\
\text { drug etanercept on the } \\
\text { metabolite profiles of } \\
\text { severe psoriasis patients }\end{array}$ & $\begin{array}{l}\text { Pretreatment: } 32 \text { with } \\
\text { mild Ps, } 32 \text { with severe } \\
\text { Ps, } 32 \text { healthy control } \\
\text { Posttreatment: } 16 \text { severe } \\
\text { patients with } 12 \text { weeks } \\
\text { Enbrel treatment }\end{array}$ & LC-HRMS & $\begin{array}{l}\text { Anti-TNF } \alpha \text { treatment } \\
\text { normalized metabolite changes } \\
\text { Perturbed pathways associated } \\
\text { with psoriasis: I) Arginine and } \\
\text { proline; } \\
\text { 2) Glycine, serine, and } \\
\text { threonine; } \\
\text { 3) Alanine, aspartate, and } \\
\text { glutamate }\end{array}$ & $\begin{array}{l}\text { Plasma levels of amino acids } \\
\text { can be used to assess Ps } \\
\text { severity and track response to } \\
\text { treatment }\end{array}$ \\
\hline |zaki et al ${ }^{79}$ & $\begin{array}{l}\text { To determine the } \\
\text { differences in platelet- } \\
\text { activating factor and } \\
\text { arachidonic acid } \\
\text { metabolites in the } \\
\text { plasma of psoriasis and } \\
\text { palmoplantar pustulosis } \\
\text { pts compared to healthy } \\
\text { controls }\end{array}$ & $\begin{array}{l}12 \text { healthy controls } \\
\text { Pretreatment: } 25 \text { Ps adults } \\
\text { and children } \\
33 \text { adults with } \\
\text { palmoplantar putulosis } \\
\text { Posttreatment: } 16 \text { Ps } \\
\text { patients } \\
\text { II palmoplantar putulosis } \\
\text { patients }\end{array}$ & $\begin{array}{l}\text { Radioimmuno } \\
\text { assay }\end{array}$ & $\begin{array}{l}\text { Ps versus control: PAF, LTB4 } \\
\text { higher in Ps } \\
\text { No difference in TXB2 and } \\
\text { PGE2 } \\
\text { Palmoplantar pustulosis } \\
\text { versus control: Similar, but } \\
\text { statistically insignificant, } \\
\text { increases in PAF, LTB4 }\end{array}$ & $\begin{array}{l}\text { PAF may contribute to the } \\
\text { acute phase of inflammation } \\
\text { in psoriasis by bolstering the } \\
\text { inflammatory response of } \\
\text { leukocytes and endothelial cells }\end{array}$ \\
\hline Kang et al ${ }^{70}$ & $\begin{array}{l}\text { To determine differences } \\
\text { in serum metabolomic } \\
\text { profiles between Ps } \\
\text { patients and healthy } \\
\text { controls and identify } \\
\text { biomarkers for Ps }\end{array}$ & $\begin{array}{l}\text { I4 Ps patients - } 15 \text { age- } \\
\text { and gender-matched } \\
\text { healthy controls }\end{array}$ & GC-MS & $\begin{array}{l}\text { Ps had higher asparagine, } \\
\text { aspartic acid, isoleucine, } \\
\text { phenylalanine, ornithine and } \\
\text { proline } \\
\text { Ps also had higher lactic acid, } \\
\text { urea } \\
\text { Ps had lower crotonic acid, } \\
\text { azelaic acid, ethanolamine, and } \\
\text { cholesterol }\end{array}$ & $\begin{array}{l}\text { Glycolysis pathway and amino } \\
\text { acid metabolic activity are } \\
\text { increased in Ps } \\
\text { Metabolite changes likely } \\
\text { due to increased demand } \\
\text { for protein biosynthesis and } \\
\text { keratinocyte hyperproliferation }\end{array}$ \\
\hline $\begin{array}{l}\text { Grattan } \\
\text { et al }{ }^{77}\end{array}$ & $\begin{array}{l}\text { To determine whether } \\
\text { low blood levels } \\
\text { of certain essential } \\
\text { fatty acids and their } \\
\text { metabolites are } \\
\text { correlated with Ps, acne } \\
\text { vulgaris, and icthyosis } \\
\text { vulgaris }\end{array}$ & $\begin{array}{l}21 \text { chronic plaque Ps } \\
\text { ( } 12 \text { mild, } 6 \text { moderate, } \\
3 \text { severe, } 17 \text { on topicals) } \\
20 \text { acne } \\
13 \text { icthyosis vulgaris } \\
35 \text { healthy volunteers }\end{array}$ & GC & $\begin{array}{l}\text { Arachidonic acid lower in all } \\
3 \text { study groups compared to } \\
\text { controls } \\
\text { Docosapentaenoic acid in all } \\
3 \text { study groups lower than } \\
\text { controls } \\
\text { DGLA was increased in Ps, } \\
\text { normal in acne, and decreased } \\
\text { in icthyosis }\end{array}$ & $\begin{array}{l}\text { Although certain EFA } \\
\text { abnormalities are shared by } \\
\text { various skin disease, the overall } \\
\text { pattern of EFA metabolism } \\
\text { abnormalities seem to be } \\
\text { unique for each disease state }\end{array}$ \\
\hline $\begin{array}{l}\text { Madsen } \\
\text { et } \mathrm{al}^{73}\end{array}$ & $\begin{array}{l}\text { To determine whether } \\
\text { metabolite concentration } \\
\text { variations in RA can lead } \\
\text { to biomarker discovery } \\
\text { which can increase } \\
\text { specificity of diagnosis in } \\
\text { early RA patients }\end{array}$ & $\begin{array}{l}25 \text { adults with RA } \\
20 \text { adults with PsA } \\
10 \text { healthy controls }\end{array}$ & $\begin{array}{l}\text { LC-MS, } \\
\text { GC-MS }\end{array}$ & $\begin{array}{l}\text { Metabolic profile of RA versus } \\
\text { PsA: Ps had lower glutamine, } \\
\text { heptanoic acid, succinate, } \\
\text { pseudouridine, inosine, } \\
\text { guanosine, arabitol, cystine, } \\
\text { cysteine, phosphoric acid } \\
\text { Pso had higher aspartic acid, } \\
\text { glutamic acid, glutamate, } \\
\text { histidine, serine, arachidonic } \\
\text { acid, cholesterol, threonic } \\
\text { acid, I-monooleoylglycerol }\end{array}$ & $\begin{array}{l}\text { Metabolic profiling can } \\
\text { help diagnose patients with } \\
\text { autoimmune diseases that lack } \\
\text { specific criteria such as PsA } \\
\text { and RA } \\
\text { Metabolic profiles can help } \\
\text { distinguish PsA from RA }\end{array}$ \\
\hline
\end{tabular}


Table 4 (Continued)

\begin{tabular}{|c|c|c|c|c|c|}
\hline Studies & Study objectives & Subjects & Techniques & Results & Implications \\
\hline Bilgiç et $\mathrm{al}^{76}$ & $\begin{array}{l}\text { To investigate the } \\
\text { dysregulation of } \\
\text { L-arginine-NO pathway } \\
\text { in Ps by assessing levels } \\
\text { of homocysteine, ADMA, } \\
\text { and L-arginine-NO } \\
\text { pathway products }\end{array}$ & $\begin{array}{l}42 \text { chronic plaque Ps } \\
48 \text { healthy controls }\end{array}$ & HPLC-MS & $\begin{array}{l}\text { Homocysteine and ADMA } \\
\text { were higher in Ps compared } \\
\text { to controls } \\
\text { PASI scores were correlated } \\
\text { with the ADMA level, and } \\
\text { L-arginine/ADMA ratio, but not } \\
\text { homocysteine, L-arginine, or } \\
\text { citrulline } \\
\text { Homocysteine was positively } \\
\text { correlated with ADMA, } \\
\text { SDMA, L-NMMA, but } \\
\text { negatively correlated with } \\
\text { L-arginine, L-arginine/ADMA }\end{array}$ & $\begin{array}{l}\text { High homocysteine and ADMA } \\
\text { in Ps increase CVD risk in Ps } \\
\text { Increased ADMA may also } \\
\text { contribute to Ps pathogenesis } \\
\text { by inhibiting L-arginine- } \\
\text { NO pathway and reducing } \\
\text { cutaneous NO, which inhibits } \\
\text { keratinocyte proliferation }\end{array}$ \\
\hline
\end{tabular}

Abbreviations: ADMA, asymmetrical dimethyl arginine; CVD, cardiovascular disease; DGLA, dihomo- $\gamma$-linolenic acid; EFA, essential fatty acids; GC, gas chromatography; HPLC, high performance liquid chromatography; HRMS, high-resolution mass spectrometry; LC, liquid chromatography; LTB4, leukotriene B4; MS, mass spectroscopy; NMMA, NG-monomethyl arginine; PASI, psoriasis area and severity index; PGE2, prostaglandin E2; Ps, psoriasis; PsA, psoriatic arthritis; RA, rheumatoid arthritis; SDMA, symmetric dimethylarginine; TNF, tumor necrosis factor; TXB2, thromboxane B2.

a paramount role in cellular protein synthesis and growth, may experience higher rates of consumption by overactive immune cells in psoriasis patients. However, asparagine experiences spontaneous deamidation and breakdown in environments of high oxidative stress, such as the psoriatic inflammatory milieu. ${ }^{47}$ Therefore, lower levels of asparagine in psoriasis patients may reflect the high cell turnover and chronic inflammatory state seen in psoriatic disease. Another key finding of the Armstrong study was the level of alpha-ketoglutaric acid, which was higher in psoriasis, but lower in psoriatic arthritis. ${ }^{47}$ In addition to its role as a citric acid cycle intermediate, alpha-ketoglutarate can be converted to glutamate, which may then be used to produce proline, a major substrate of collagen synthesis. ${ }^{68}$ Thus, alpha-ketoglutaric acid may be high in psoriasis as a result of increased energy demand secondary to hyperproliferation, but low in psoriatic arthritis due to rapid consumption for collagen synthesis. ${ }^{69}$ Similarly, other serum-based metabolomic studies have found amino acid changes consistent with the model of high cell turnover suggested by Armstrong. A 2015 LC-MS study conducted by Kamleh et $\mathrm{al}^{69}$ and a 2016 GC-MS study by Kang et al ${ }^{70}$ revealed increased activity in the urea cycle and the arginine and proline pathway. This pattern is also found in other hyperproliferative states, such as wound healing. ${ }^{71}$ Together, these studies show that psoriasis has metabolic effects that are not limited to the skin, but are appreciable at a systemic level. Interestingly, Kamleh et al saw increased levels of isoleucine ${ }^{69}$ and Kang et al found elevations in isoleucine, leucine, and valine. ${ }^{70}$ Incidentally, these branched chain fatty acids are also elevated in diabetes and cardiovascular disease and may provide a biochemical link between psoriasis and its systemic cardiometabolic comorbidities. . $^{42,72}$
Serum amino acids in psoriasis patients not only provided insights into disease pathogenesis, but may also be useful as biomarkers for disease severity and monitoring of therapeutic response. For example, the Kamleh group correlated increases in urea cycle amino acids, such as ornithine, arginine, and citrulline with psoriasis severity as measured by psoriasis area and severity index (PASI) score. ${ }^{69}$ In addition, increases in proline, and hydroxyproline, amino acids important for collagen synthesis, were also correlated with disease severity and authors suggested that hydroxyproline may be an indicator of psoriatic arthritis. Furthermore, Kamleh et al ${ }^{69}$ found that etanercept therapy normalized the concentrations of ornithine, arginine, threonine, methionine, glutamine, glycine, citrulline, and proline in psoriasis patients to that of healthy controls. These results suggest that amino acid biomarkers may be used to guide therapy and identify patients at risk of psoriatic arthritis and complications from more severe disease.

Serum-based metabolomics has also been used to distinguish psoriatic disease from other autoimmune conditions. Using a combination of LC-MS and GC-MS, Madsen et al compared serum metabolites between patients with rheumatoid arthritis, psoriatic arthritis, and healthy controls. Their study identified characteristic profiles of metabolite changes that could be used to differentiate the serum of psoriatic arthritis from rheumatoid arthritis with a sensitivity of $90 \%$ and a specificity of $94 \%{ }^{73}$ Among other metabolite changes, patients with psoriatic arthritis were found to have higher levels of glutamic acid and serine and lower levels of glutamine relative to rheumatoid arthritis. This study, like the one reported by Kamleh et al, also found statistically different concentrations of metabolites in study group patients 
versus control patients, ${ }^{69}$ further underscoring the potential of metabolomic biomarkers in detecting and classifying disease. Studying the metabolic profiles of these patients and standardizing concentration criteria could lead to novel diagnostic techniques with improved specificity in clinically equivocal cases.

Understanding metabolic perturbations in psoriasis can also inform disease prognosis and comorbidities. In recent years, cardiovascular disease has been identified as a significant comorbidity in the psoriatic population, perhaps related to high levels of inflammation. ${ }^{74,75}$ The amino acid, homocysteine, has been independently associated with an increased risk of cardiovascular events, which is thought to be mediated by the accumulation of asymmetrical dimethyl arginine (ADMA), a NOS inhibitor that causes endothelial dysfunction. ${ }^{76}$ A 2015 study by Bilgiç et al measured plasma homocysteine, ADMA, and other NOS pathway metabolites in psoriasis patients to further define the relationship between hyperhomocysteinemia, psoriasis, and cardiovascular risk. Results from this study demonstrated that although both homocysteine and ADMA concentrations were significantly increased in psoriasis patients versus healthy controls, the severity of psoriasis (assessed with PASI scoring) was only positively correlated with ADMA and the ratio of ADMA to L-arginine, but not homocysteine. ${ }^{76}$ Thus, while ADMA's inhibitory effects on cutaneous NOS may reduce epidermal NO, thereby promoting keratinocyte hyperproliferation in psoriasis, its inhibition of endothelial NOS may contribute to the increased cardiovascular risk in psoriasis patients. ${ }^{76}$ Consequently, serum ADMA has the potential to be a useful predictor of subclinical cardiovascular disease in psoriasis patients.

In addition to lipids and amino acids, arachidonic acid metabolites have also been investigated in the serum of psoriasis patients. In contrast to skin metabolomics studies, several blood-based studies have found that arachidonic acid levels were lower in psoriasis. ${ }^{47,69,77}$ However, another study found LTB4 and platelet activating factor, a chemotactic agent and stimulator of the arachidonic acid pathway, ${ }^{78}$ were present at higher concentrations in psoriasis patients. ${ }^{79}$ Platelet activating factor is thought to bolster the inflammatory response of leukocytes and endothelial cells in both psoriasis and palmoplantar pustulosis. ${ }^{79}$

Overall, blood-based metabolomics offers a global picture of how psoriatic disease affects the body's metabolic pathways. Although it may be difficult to determine if circulating biochemical shifts are the cause or effect of psoriatic disease, blood metabolomics can be used to understand the systemic changes in psoriasis that lead to metabolic comorbidities.
This avenue of research is particularly interesting because psoriasis patients had elevated levels of phenalanine ${ }^{45,69,70}$ and isoleucine, ${ }^{69,70}$ which have been implicated in obesity, diabetes, and cardiovascular disease. ${ }^{4,22,72}$ Increased levels of these metabolites could potentially serve as a marker of future cardiometabolic disease and guide the management of psoriatic comorbidities. The blood is also an excellent medium for detecting exogenous metabolites from the gut or skin microbiome that may influence host inflammatory pathways. Blood-based metabolome studies in cardiovascular and diabetes research have already revealed bacterial metabolites that are transferred to the host and promote insulin resistance ${ }^{24}$ and atherosclerotic plaque formation. ${ }^{6,23}$ Thus, the profile of bacterial metabolites may be a more reliable indicator of disease risk than shifts in particular microbial species. In addition to the microbiome, the effects of other exogenous factors, such as diet and stress, can also be assessed through blood metabolomics. A better understanding of the mechanistic links between the microbiome, diet, psoriasis, and its metabolic comorbidities can lead to new strategies for cardiometabolic screening and disease management.

\section{Urine}

The utility of a urine-based approach to metabolomic analyses can be appreciated for its easy, noninvasive collection method, and its richness in body metabolites and other noncellular products. Currently in the biomedical literature, only a small number of metabolomics studies analyze urine from psoriasis and/or psoriatic arthritis patients using proton NMR ( ${ }^{1} \mathrm{H}$ NMR) or LC-MS attempting to identify distinct biomarkers that indicate psoriatic disease activity and/or severity and distinct biomarkers to predict and monitor response to the treatment (Table 5).

In 2015, a study by Setkowicz et al identified baseline biomarkers in patients with psoriasis and psoriatic arthritis by analyzing the urinary metabolites of $12(\mathrm{~S})$-HETE in relation to the severity of their skin lesions. LC-MS showed significantly higher tetranor-12(S)-HETE metabolite excretion in urine of patients with psoriasis whereas 12(S)-HETE was decreased relative to controls. ${ }^{80}$ The study proposed that an altered, accelerated metabolism of 12(S)-HETE in psoriasis patients explained the increase in the urinary metabolite product. ${ }^{80} 12$ (S)-HETE is an arachidonate LOX product that acts as a potent leukocyte chemoattractant, which has been shown to be found in increased amounts in lesional skin in psoriasis. The accelerated metabolism theory at least partly supports the levels of 12(S)-HETE and tetranor-12(S)-HETE found in psoriasis patients. This metabolic profile and levels, 
however, did not correlate with disease activity or severity. The study concluded that the accelerated conversion of 12(S)-HETE to tetranor-12(S)-HETE may be secondary to skin inflammation-induced microsomal beta-oxidation and may be useful as a marker for psoriasis. ${ }^{80}$

Other potential urinary biomarkers were investigated by Alonso et al who compared the metabolite profiles of psoriasis, psoriatic arthritis, rheumatoid arthritis, Crohn's disease, ulcerative colitis, and systemic lupus erythematous. Psoriasis and psoriatic arthritis were found to have lower levels of citrate, alanine, methylsuccinate, trigonelline, carnitine, and hippurate relative to controls. ${ }^{81}$ In psoriatic arthritis patients, citrate levels were inversely correlated with disease activity ${ }^{81}$ and may useful for monitoring of therapeutic response and disease severity. Subsequent clustering analysis demonstrated that the urine metabolite profiles could be divided into three main groups. Psoriasis and psoriatic arthritis comprised one group, sharing five metabolite associations, whereas the second group of Crohn's disease and ulcerative colitis shared six metabolite associations. ${ }^{81}$ The third group, composed of rheumatoid arthritis and lupus samples, shared three metabolite associations. Like the blood-based study conducted by Madsen's group, these results suggest that psoriatic disease and rheumatoid arthritis have distinct metabolite profiles that may be used to aid in differential diagnosis.

Urinary biomarkers may also help predict or monitor treatment response. A 2013 study by Kapoor et al analyzed changes in urinary metabolic profiles before and during therapy with anti-tumor necrosis factor-alpha (anti-TNF $\alpha$ ) medications infliximab or etanercept in 20 psoriatic arthritis patients and 16 rheumatoid arthritis patients by ${ }^{1} \mathrm{H}$ NMR. Both psoriatic arthritis and rheumatoid arthritis patients had higher levels of glutamine, phenylacetic acid, and histamine in baseline urine samples and higher levels of methylamine and creatinine in the 12 -week urine samples during treatment. ${ }^{82}$ Elevated levels of these amino acids and their byproducts can be explained by increase in cell turnover and accelerated muscle breakdown due to chronic TNF $\alpha$ stimulation causing a cachexia-like effect. ${ }^{82}$ Urinary metabolite profiles may, therefore, be used to predict and monitor treatment response. Differences in metabolic changes between rheumatoid arthritis and psoriatic arthritis with anti-TNF $\alpha$ were not investigated due to small patient numbers. However, it was found that infliximab and etanercept alter metabolites in the urine differently. With infliximab treatment, there were high urinary metabolite levels of hippuric acid, citrate, and lactic acid; whereas with etanercept treatment, there were high urinary metabolite levels of choline, phenylacetic acid, urea, creatine, and methylamine. ${ }^{82}$ Although infliximab and etanercept were previously thought to act primarily on TNF $\alpha$, the unexpected difference in urinary metabolite profiles may reflect differences in unknown additional mechanisms of action. ${ }^{82}$ Although etanercept and infliximab share immunomodulating effects, they were found to induce different patterns of gene suppression. Infliximab downregulated many Th1 genes, whereas etanercept suppressed genes promoting follicular dendritic cell development and lymphoid neo-organogenesis. ${ }^{83}$

The overall conclusions of these studies highlight the possible role of urine metabolomics as a convenient, noninvasive method of identifying biomarker profiles, predicting therapeutic response, and monitoring long-term treatment outcomes. Urine metabolomics is thus, exceptionally well suited for application to personalized medicine. In the future, the urine metabolome may be used to biochemically characterize and distinguish between psoriatic subtypes and tailor treatment to individual metabolic phenotypes. However, investigations on urinary metabolomics analyses in psoriasis and psoriatic arthritis patients are scarce and current data on discriminating urinary biomarkers for psoriasis and psoriatic arthritis are not specific. Further research is warranted involving a greater number of cohorts to identify characteristic urinary metabolic profiles in psoriasis and psoriatic arthritis.

\section{Conclusion}

Metabolomics has the potential to greatly transform our understanding of psoriatic disease. Already, investigations of the metabolome in skin, blood, and urine samples have revealed interesting trends in metabolite differences between healthy individuals and those with psoriasis. Targeted analyses of the arachidonic acid pathway demonstrate increases in leukotriene branch intermediates in psoriatic skin, ${ }^{62,63,65}$ and urine, ${ }^{80}$ although findings in blood samples were mixed. ${ }^{69,77,79}$ These results suggest that leukotrienes may play an important role in the local inflammatory milieu, but may not be a significant driver of systemic inflammation.

While targeted analyses have enhanced our understanding of known inflammatory pathways intermediates in psoriasis, untargeted metabolomics studies have uncovered new metabolites linked to psoriatic disease. For example, untargeted studies in both blood and skin samples have reported increased levels of taurine, ${ }^{46,49,69}$ glutamic acid, ${ }^{45,46,69}$ and phenylalanine..$^{45,69,70}$ These perturbations in endogenous metabolites have not previously been described in association with psoriasis and represent some of the unique contributions untargeted metabolomics has made to psoriasis research. 
Table 5 Metabolomics studies of psoriasis using urine samples

\begin{tabular}{|c|c|c|c|c|c|}
\hline Studies & Study objectives & Subjects & Techniques & Key results & Implications \\
\hline Alonso et $\mathrm{al}^{81}$ & $\begin{array}{l}\text { Identification of } \\
\text { diagnostic biomarkers } \\
\text { in urine metabolome of } \\
\text { RA, Ps, PsA, UC, CD, } \\
\text { and SLE }\end{array}$ & $\begin{array}{l}\text { Discovery: } 200 \text { in each } \\
\text { of } 6 \text { disease cohorts (RA, } \\
\text { PsA, Ps, UC, CD, and SLE) } \\
100 \text { healthy controls } \\
\text { Validation: } 200 \text { in each of } \\
6 \text { disease cohorts (RA, } \\
\text { PsA, Ps, UC, CD, and SLE) } \\
200 \text { healthy controls }\end{array}$ & 'H NMR & $\begin{array}{l}\text { Metabolite profiles cluster } \\
\text { into } 3 \text { groups (Ps and PsA, } \\
\text { CD and UC, and RA and SLE) } \\
\text { Ps and PsA had lower citrate, } \\
\text { alanine, methylsuccinate, } \\
\text { trigonelline, carnitine, } \\
\text { hippurate compared to } \\
\text { controls } \\
\text { Citrate inverse correlated } \\
\text { with disease activity in PsA }\end{array}$ & $\begin{array}{l}\text { Metabolite profiles can } \\
\text { be used to diagnose } \\
\text { and distinguish between } \\
\text { autoimmune diseases, such } \\
\text { as PsA and RA }\end{array}$ \\
\hline Kapoor et a ${ }^{82}$ & $\begin{array}{l}\text { Determining changes in } \\
\text { urine metabolic profiles } \\
\text { in RA and PsA patients } \\
\text { before and during } \\
\text { therapy with anti-TNF } \\
\text { to predict response }\end{array}$ & $\begin{array}{l}\text { I6 RA patients } \\
20 \text { PsA patients before } \\
\text { and during therapy with } \\
\text { infliximab or etanercept }\end{array}$ & 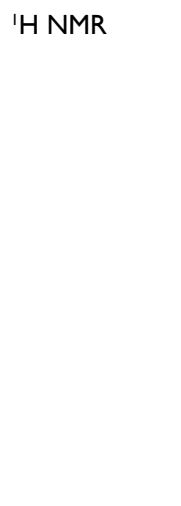 & $\begin{array}{l}\text { Baseline RA, PsA } \\
\text { Higher glutamine, } \\
\text { phenylacetic acid, histamine } \\
\text { After treatment in RA, PsA } \\
\text { Infliximab treatment } \\
\text { increased hippuric acid, } \\
\text { citrate, lactic acid } \\
\text { Etanercept increased choline, } \\
\text { phenylacetic acid, urea, } \\
\text { creatine, and methylamine } \\
\text { Higher levels of methylamine } \\
\text { and creatinine at } 12 \text { weeks }\end{array}$ & $\begin{array}{l}\text { Metabolomic profiles may be } \\
\text { used to predict and monitor } \\
\text { response to anti-TNF } \\
\text { therapy in PsA and RA }\end{array}$ \\
\hline Setkowicz et al ${ }^{80}$ & $\begin{array}{l}\text { Determine frequencies } \\
\text { of the genetic variants } \\
\text { ALOXI } 2 \text { rs I I } 26667 \\
\text { and ALOXI5 } \\
\text { rs II568070 in cases and } \\
\text { controls, and compare } \\
\text { urinary metabolites of } \\
\text { I2(S)-HETE in Ps and } \\
\text { healthy controls }\end{array}$ & $\begin{array}{l}200 \text { Patients Ps stratified } \\
\text { by severity }\end{array}$ & HPLC-MS-MS & $\begin{array}{l}\text { Ps had higher urinary } \\
\text { Tetranor-I2(S)-HETE, lower } \\
\text { I2(S)-HETE, but levels did } \\
\text { not correlate severity } \\
\text { No difference in genotype } \\
\text { and allelic distributions of } \\
\text { ALOXI2 rs I I } 26667 \text { and } \\
\text { ALOXI5 rs I I568070 in Ps } \\
\text { and controls }\end{array}$ & $\begin{array}{l}\text { Systemic metabolism of } \\
\text { I2(S)-HETE is accelerated } \\
\text { in psoriasis and this cannot } \\
\text { be explained by genetic } \\
\text { differences in ALOXI2 } \\
\text { rs I I } 26667 \text { and ALOXI5 } \\
\text { rs I I568070 polymorphisms }\end{array}$ \\
\hline
\end{tabular}

Abbreviations: CD, Crohn's disease; HETE, hydroxyeicosatetraenoic acid; 'H NMR, proton nuclear magnetic resonance; HPLC, high performance liquid chromatography; MS-MS, tandem mass spectrometry; Ps, psoriasis; PsA, psoriatic arthritis; RA, rheumatoid arthritis; SLE, systemic lupus erythematous; TNF, tumor necrosis factor; UC, ulcerative colitis.

The findings not only provide a new layer of information about disease processes, such as local and systemic increases in cell proliferation, inflammation, and cell turnover, but also suggest novel biomarkers that can help us characterize psoriatic subtypes and differentiate psoriasis and psoriatic arthritis from similar conditions. As Madsen et al have demonstrated, panels of metabolites can potentially aid in next generation diagnosis with high sensitivity and specificity. ${ }^{73}$ Furthermore, the untargeted metabolomics approach has revealed new avenues for therapeutic advancement. Despite improved efficacy over topicals and nonselective traditional systemics, expensive biologics have notoriously high rates of relapse. Currently, anti-TNF $\alpha$ biologics, such as etanercept, infliximab, and adalimumab have relapse rates of $85 \%,{ }^{84}$ $72 \%,{ }^{84}$ and $62 \%,{ }^{85}$ respectively. Studying the metabolites that did not normalize with topical corticosteroids and antiTNF therapies ${ }^{49,69,82}$ may offer insight into the mechanisms for disease relapse and help identify new pathways that can be targeted for a sustained cure.

Although metabolomics has proved to be a valuable research tool in psoriasis research, it has important limitations, such as cost, lack of standard diagnostic concentration criteria, and need for mechanistic validation. For example, the development of a standard set of concentration criteria has been hampered by technical challenges in absolute metabolite quantification. In LC-MS, a metabolite's signal intensity depends not only on concentration but also on the matrix in which the sample is analyzed. ${ }^{33}$ Ion suppression and other matrix effects can cause inaccurate measurements of metabolite concentration. ${ }^{33}$ Stable isotope standards can 
be a potential solution, but costs are often prohibitive for large scale metabolomics. ${ }^{33}$ While NMR has better absolute quantification capabilities, it is less sensitive and its use in untargeted metabolomics suffers from problems relating to peak overlap, which can compromise accurate determinations of peak area in NMR spectra ${ }^{86}$ Consequently, untargeted metabolomics studies are, generally, only semiquantitative and typically report findings in terms of relative quantification (i.e., fold change) instead of absolute concentration. ${ }^{31}$ It is relatively easier, although still costly, to determine absolute metabolite quantities in targeted metabolomics. Recently, the development of commercial kits with standard mixtures of stable isotope labeled internal standards have allowed for a more standardized and cost-effective approach to metabolomics. ${ }^{31}$ As absolute quantification capabilities improve, diagnostic standards can be developed for clinical use. Another key limitation of metabolomics data are the potential for overinterpretation. While pathway and network analyses have provided crucial biologic context to metabolomics data, it is important to note that these data provide evidence of association and not necessarily causation. Further mechanistic studies are needed to understand its role in the pathogenesis of psoriatic disease.

One powerful way to understanding the pathogenic role of metabolite perturbations is to combine metabolomics datasets from other "-omics" fields. An integrated "-omics" approach would allow researchers to account for influences from genetic, environmental, dietary, and microbial factors in a multilevel biologic phenotype that can be used for personalized medicine. Already, several different approaches have been developed for the integration of multiple dimensions of "-omics" data, such as concatenation-based integration, transformation-based integration, and model-based integration. ${ }^{87}$ For example, Bayesian networks are a concatenation-based integration strategy that can be used to model conditional dependencies between gene expression, proteins, and metabolites. ${ }^{88}$ Recently, Guo et al have used a combination of blood-based metabolomics and whole exome sequencing to assess the biologic significance and penetrance of genetic mutations in a cohort of 80 healthy volunteers who were free of diagnosed disease at the time of sampling. ${ }^{89}$ This study identified abnormalities in metabolites involved in lipolysis, glycolysis, and branched chain amino acid metabolism in subjects with genetic mutations associated with diabetes who were later diagnosed with the disease. ${ }^{89}$ Guo's study provides an example of how metabolomics data can provide insight into the clinical significance of other "-omics" data especially in detecting preclinical disease and assessing personalized disease risk. ${ }^{89} \mathrm{~A}$ similar strategy can be useful for individualized medical management in psoriasis, which has complex, multifactorial determinants of disease risk and phenotype. Moving forward, the next challenge of personalized medicine in psoriatic disease will lie in translating massive, multidimensional files of individualized data to better patient care in the clinical setting.

\section{Acknowledgments}

This study was supported in part by grants to Wilson Liao (NIH R01 AR065174, NIH U01 AI119125, National Psoriasis Foundation Translational Research Award). Di Yan acknowledges support from a National Psoriasis Foundation Fellowship.

\section{Disclosure}

The authors report no conflicts of interest in this work.

\section{References}

1. Pauling L, Robinson AB, Teranishi R, Cary P. Quantitative analysis of urine vapor and breath by gas-liquid partition chromatography. Proc Natl Acad Sci U S A. 1971;68(10):2374-2376.

2. Oliver SG, Winson MK, Kell DB, Baganz F. Systematic functional analysis of the yeast genome. Trends Biotechnol. 1998;16(9):373-378.

3. Tweeddale H, Notley-McRobb L, Ferenci T. Effect of slow growth on metabolism of Escherichia coli, as revealed by global metabolite pool ("metabolome") analysis. J Bacteriol. 1998;180(19):5109-5116.

4. Wang TJ, Larson MG, Vasan RS, et al. Metabolite profiles and the risk of developing diabetes. Nat Med. 2011;17(4):448-453.

5. Palmer ND, Stevens RD, Antinozzi PA, et al. Metabolomic profile associated with insulin resistance and conversion to diabetes in the Insulin Resistance Atherosclerosis Study. J Clin Endocrinol Metab. 2015; 100(3):E463-E468.

6. Wang Z, Klipfell E, Bennett BJ, et al. Gut flora metabolism of phosphatidylcholine promotes cardiovascular disease. Nature. 2011;472(7341): $57-63$.

7. Jung J, Kim SH, Lee HS, et al. Serum metabolomics reveals pathways and biomarkers associated with asthma pathogenesis. Clin Exp Allergy. 2013;43(4):425-433.

8. Giera M, Ioan-Facsinay A, Toes R, et al. Lipid and lipid mediator profiling of human synovial fluid in rheumatoid arthritis patients by means of LC-MS/MS. Biochim Biophys Acta. 2012;1821(11):1415-1424.

9. Romick-Rosendale LE, Brunner HI, Bennett MR, et al. Identification of urinary metabolites that distinguish membranous lupus nephritis from proliferative lupus nephritis and focal segmental glomerulosclerosis. Arthritis Res Ther. 2011;13(6):R199.

10. Trushina E, Mielke MM. Recent advances in the application of metabolomics to alzheimer's disease. Biochim Biophys Acta. 2014; 1842(8):1232-1239.

11. Behrends V, Bell TJ, Liebeke M, et al. Metabolite profiling to characterize disease-related bacteria: gluconate excretion by Pseudomonas aeruginosa mutants and clinical isolates from cystic fibrosis patients. J Biol Chem. 2013;288(21):15098-15109.

12. Schoen C, Kischkies L, Elias J, Ampattu BJ. Metabolism and virulence in Neisseria meningitidis. Front Cell Infect Microbiol. 2014;4:114.

13. Yang J, Xu G, Zheng Y, et al. Diagnosis of liver cancer using HPLCbased metabonomics avoiding false-positive result from hepatitis and hepatocirrhosis diseases. J Chromatogr B Analyt Technol Biomed Life Sci. 2004;813(1-2):59-65. 
14. Kim K, Aronov P, Zakharkin SO, et al. Urine metabolomics analysis for kidney cancer detection and biomarker discovery. Mol Cell Proteomics. 2009;8(3):558-570.

15. Katz-Brull R, Seger D, Rivenson-Segal D, Rushkin E, Degani H. Metabolic markers of breast cancer: enhanced choline metabolism and reduced choline-ether-phospholipid synthesis. Cancer Res. 2002;62(7):1966-1970.

16. Scott DA, Richardson AD, Filipp FV, et al. Comparative metabolic flux profiling of melanoma cell lines: beyond the Warburg effect. $J$ Biol Chem. 2011;286(49):42626-42634.

17. Abaffy T, Moller MG, Riemer DD, Milikowski C, DeFazio RA. Comparative analysis of volatile metabolomics signals from melanoma and benign skin: a pilot study. Metabolomics. 2013;9(5):998-1008.

18. Mun JH, Lee H, Yoon D, Kim BS, Kim MB, Kim S. Discrimination of basal cell carcinoma from normal skin tissue using high-resolution magic angle spinning 1H NMR spectroscopy. PLoS One. 2016;11(3):e0150328.

19. Carichon M, Pallet N, Schmitt C, et al. Urinary metabolic fingerprint of acute intermittent porphyria analyzed by (1)H NMR spectroscopy. Anal Chem. 2014;86(4):2166-2174.

20. Assfalg M, Bortoletti E, D’Onofrio M, et al. An exploratory (1) $\mathrm{H}$-nuclear magnetic resonance metabolomics study reveals altered urine spectral profiles in infants with atopic dermatitis. Br J Dermatol. 2012;166(5):1123-1125.

21. Cho K, Moon JS, Kang JH, et al. Combined untargeted and targeted metabolomic profiling reveals urinary biomarkers for discriminating obese from normal-weight adolescents. Pediatr Obes. Epub 2016 Feb 22.

22. Du F, Virtue A, Wang H, Yang XF. Metabolomic analyses for atherosclerosis, diabetes, and obesity. Biomark Res. 2013;1(1):17.

23. Koeth RA, Wang Z, Levison BS, et al. Intestinal microbiota metabolism of L-carnitine, a nutrient in red meat, promotes atherosclerosis. Nat Med. 2013;19(5):576-585.

24. Pedersen HK, Gudmundsdottir V, Nielsen HB, et al. Human gut microbes impact host serum metabolome and insulin sensitivity. Nature. 2016;535(7612):376-381.

25. Smith CA, Want EJ, O'Maille G, Abagyan R, Siuzdak G. XCMS: processing mass spectrometry data for metabolite profiling using nonlinear peak alignment, matching, and identification. Anal Chem. 2006;78(3):779-787.

26. Smith CA, O'Maille G, Want EJ, et al. METLIN: a metabolite mass spectral database. Ther Drug Monit. 2005;27(6):747-751.

27. Wishart DS, Knox C, Guo AC, et al. HMDB: a knowledgebase for the human metabolome. Nucleic Acids Res. 2009;37(Database issue):D603-D610.

28. Kanehisa M, Goto S, Hattori M, et al. From genomics to chemical genomics: new developments in KEGG. Nucleic Acids Res 2006;34(Database issue):D354-D357.

29. Xia J, Mandal R, Sinelnikov IV, Broadhurst D, Wishart DS. MetaboAnalyst 2.0 - a comprehensive server for metabolomic data analysis. Nucleic Acids Res. 2012;40(Web Server issue):W127-W133.

30. Grapov D, Wanichthanarak K, Fiehn O. MetaMapR: pathway independent metabolomic network analysis incorporating unknowns. Bioinformatics. 2015;31(16):2757-2760.

31. Wishart DS. Emerging applications of metabolomics in drug discovery and precision medicine. Nat Rev Drug Discov. 2016;15(7):473-484.

32. Zhang A, Sun H, Wang P, Han Y, Wang X. Modern analytical techniques in metabolomics analysis. Analyst. 2012;137(2):293-300.

33. Lei Z, Huhman DV, Sumner LW. Mass spectrometry strategies in metabolomics. J Biol Chem. 2011;286(29):25435-25442.

34. Liu Y, Fu X, Bai Y, et al. Improvement of reproducibility and sensitivity of CE analysis by using the capillary coated dynamically with carboxymethyl chitosan. Anal Bioanal Chem. 2011;399(8):2821-2829.

35. Ramautar R, Torano JS, Somsen GW, de Jong GJ. Evaluation of CE methods for global metabolic profiling of urine. Electrophoresis. 2010;31(14):2319-2327.

36. Emwas A-HM, Salek RM, Griffin JL, Merzaban J. NMR-based metabolomics in human disease diagnosis: applications, limitations, and recommendations. Metabolomics. 2013;9(5):1048-1072.
37. Xu D, Vigneron D. Magnetic resonance spectroscopy imaging of the newborn brain - a technical review. Semin Perinatol. 2010;34(1):20-27.

38. Santagata S, Eberlin LS, Norton I, et al. Intraoperative mass spectrometry mapping of an onco-metabolite to guide brain tumor surgery. Proc Natl Acad Sci U S A. 2014;111(30):11121-11126.

39. Bouslimani A, Porto C, Rath CM, et al. Molecular cartography of the human skin surface in 3D. Proc Natl Acad Sci U S A. 2015;112(17): E2120-E2129.

40. Larive CK, Barding GA Jr, Dinges MM. NMR spectroscopy for metabolomics and metabolic profiling. Anal Chemy. 2015;87(1):133-146.

41. Bottomley PA, Hardy CJ, Roemer PB. Phosphate metabolite imaging and concentration measurements in human heart by nuclear magnetic resonance. Magn Reson Med. 1990;14(3):425-434.

42. Patti GJ, Yanes O, Siuzdak G. Innovation: metabolomics: the apogee of the omics trilogy. Nat Rev Mol Cell Biol. 2012;13(4):263-269.

43. Bathen TF, Sitter B, Sjobakk TE, Tessem MB, Gribbestad IS. Magnetic resonance metabolomics of intact tissue: a biotechnological tool in cancer diagnostics and treatment evaluation. Cancer Res. 2010;70(17):6692-6696.

44. van Waarde A, Elsinga PH. Proliferation markers for the differential diagnosis of tumor and inflammation. Curr Pharm Design. 2008;14(31):3326-3339.

45. Dutkiewicz EP, Hsieh KT, Wang YS, Chiu HY, Urban PL. Hydrogel micropatch and mass spectrometry-assisted screening for psoriasisrelated skin metabolites. Clin Chem. 2016;62(8):1120-1128.

46. Kim YH, Orenberg EK, Faull KF, Wade-Jardetzky NG, Jardetzky O. 1H NMR spectroscopy: an approach to evaluation of diseased skin in vivo. J Invest Dermatol. 1989;92(2):210-216.

47. Armstrong AW, Wu J, Johnson MA, et al. Metabolomics in psoriatic disease: pilot study reveals metabolite differences in psoriasis and psoriatic arthritis. F1000Res. 2014;3:248.

48. Koch B, Schroder MT, Schafer G, Schauder P. Comparison between transport and degradation of leucine and glutamine by peripheral human lymphocytes exposed to concanavalin A. J Cell Physiol. 1990;143(1):94-99.

49. Sitter B, Johnsson MK, Halgunset J, Bathen TF. Metabolic changes in psoriatic skin under topical corticosteroid treatment. BMC Dermatol. 2013;13:8.

50. Neurauter G, Schrocksnadel K, Scholl-Burgi S, et al. Chronic immune stimulation correlates with reduced phenylalanine turnover. Curr Drug Metab. 2008;9(7):622-627.

51. Marcinkiewicz J, Kontny E. Taurine and inflammatory diseases. Amino Scids. 2014;46(1):7-20.

52. Schuller-Levis GB, Park E. Taurine and its chloramine: modulators of immunity. Neurochem Res. 2004;29(1):117-126.

53. Gilmour JW, Vestey JP, Norval M. The effect of UV therapy on immune function in patients with psoriasis. Br J Dermatol. 1993;129(1):28-38.

54. Shuster S, Johnson C. The abnormality of sweat duct function in psoriasis. Br J Dermatol. 1969;81(11):846-850.

55. Ishida-Yamamoto A, Senshu T, Takahashi H, Akiyama K, Nomura K, Iizuka H. Decreased deiminated keratin K1 in psoriatic hyperproliferative epidermis. J Invest Dermatol. 2000;114(4):701-705.

56. Abeyakirthi S, Mowbray M, Bredenkamp N, et al. Arginase is overactive in psoriatic skin. Br J Dermatol. 2010;163(1):193-196.

57. Bruch-Gerharz D, Schnorr O, Suschek C, et al. Arginase 1 overexpression in psoriasis: limitation of inducible nitric oxide synthase activity as a molecular mechanism for keratinocyte hyperproliferation. Am J Pathol. 2003;162(1):203-211.

58. Krischel V, Bruch-Gerharz D, Suschek C, Kroncke KD, Ruzicka T, KolbBachofen V. Biphasic effect of exogenous nitric oxide on proliferation and differentiation in skin derived keratinocytes but not fibroblasts. J Invest Dermatol. 1998;111(2):286-291.

59. Dennis EA, Norris PC. Eicosanoid storm in infection and inflammation. Nat Rev Immunol. 2015;15(8):511-523.

60. Grabbe J, Czarnetzki BM, Rosenbach T, Mardin M. Identification of chemotactic lipoxygenase products of arachidonate metabolism in psoriatic skin. J Invest Dermatol. 1984;82(5):477-479. 
61. Sadik CD, Sezin T, Kim ND. Leukotrienes orchestrating allergic skin inflammation. Exp Dermatol. 2013;22(11):705-709.

62. Hammarström S, Hamberg M, Samuelsson B, Duell EA, Stawiski M, Voorhees JJ. Increased concentrations of nonesterified arachidonic acid, 12L-hydroxy-5,8,10,14-eicosatetraenoic acid, prostaglandin E2, and prostaglandin F2alpha in epidermis of psoriasis. Proc Natl Acad Sci U SA. 1975;72(12):5130-5134.

63. Barr RM, Wong E, Mallet AI, Olins LA, Greaves MW. The analysis of arachidonic acid metabolites in normal, uninvolved and lesional psoriatic skin. Prostaglandins. 1984;28(1):57-65.

64. Ruzicka T, Simmet T, Peskar BA, Ring J. Skin levels of arachidonic acid-derived inflammatory mediators and histamine in atopic dermatitis and psoriasis. J Invest Dermatol. 1986;86(2):105-108.

65. Brain S, Camp R, Dowd P, Black AK, Greaves M. The release of leukotriene B4-like material in biologically active amounts from the lesional skin of patients with psoriasis. J Invest Dermatol. 1984;83(1):70-73.

66. Millsop JW, Bhatia BK, Debbaneh M, Koo J, Liao W. Diet and psoriasis, part III: role of nutritional supplements. J Am Acad Dermatol. 2014;71(3):561-569.

67. Spur EM, Decelle EA, Cheng LL. Metabolomic imaging of prostate cancer with magnetic resonance spectroscopy and mass spectrometry. Eur J Nucl Med Mol Imaging. 2013;40(Suppl 1):S60-S71.

68. Wu N, Yang M, Gaur U, Xu H, Yao Y, Li D. Alpha-ketoglutarate: physiological functions and applications. Biomol Ther (Seoul). 2016;24(1):1-8.

69. Kamleh MA, Snowden SG, Grapov D, et al. LC-MS metabolomics of psoriasis patients reveals disease severity-dependent increases in circulating amino acids that are ameliorated by anti-TNFalpha treatment. J Proteome Res. 2015;14(1):557-566.

70. Kang H, Li X, Zhou Q, et al. Exploration of candidate biomarkers for human psoriasis based on GC-MS serum metabolomics. Br J Dermatol. Epub 2016 Aug 26.

71. Albina JE, Mills CD, Henry WL Jr, Caldwell MD. Temporal expression of different pathways of 1-arginine metabolism in healing wounds. J Immunol. 1990;144(10):3877-3880.

72. Ho JE, Larson MG, Ghorbani A, et al. Metabolomic profiles of body mass index in the framingham heart study reveal distinct cardiometabolic phenotypes. PLoS One. 2016;11(2):e0148361.

73. Madsen RK, Lundstedt T, Gabrielsson J, et al. Diagnostic properties of metabolic perturbations in rheumatoid arthritis. Arthritis Res Ther. 2011;13(1):R19.

74. Abuabara K, Azfar RS, Shin DB, Neimann AL, Troxel AB, Gelfand JM. Cause-specific mortality in patients with severe psoriasis: a population-based cohort study in the U.K. Br J Dermatol. 2010;163(3): 586-592.
75. Gelfand JM, Yeung H. Metabolic syndrome in patients with psoriatic disease. J Rheumatol Suppl. 2012;89:24-28.

76. Bilgiç Ö, Altinyazar HC, Baran H, Ünlü A. Serum homocysteine, asymmetric dimethyl arginine (ADMA) and other arginine-NO pathway metabolite levels in patients with psoriasis. Arch Dermatol Res. 2015;307(5):439-444.

77. Grattan C, Burton JL, Manku M, Stewart C, Horrobin DF. Essentialfatty-acid metabolites in plasma phospholipids in patients with ichthyosis vulgaris, acne vulgaris and psoriasis. Clin Exp Dermatol. 1990; 15(3):174-176.

78. Montrucchio G, Alloatti G, Camussi G. Role of platelet-activating factor in cardiovascular pathophysiology. Physiol Rev. 2000;80(4):1669-1699.

79. Izaki S, Yamamoto $\mathrm{T}$, Goto $\mathrm{Y}$, et al. Platelet-activating factor and arachidonic acid metabolites in psoriatic inflammation. Br J Dermatol. 1996;134(6):1060-1064.

80. Setkowicz M, Mastalerz L, Gielicz A, Wojas-Pelc A, Sanak M. Lack of association of ALOX12 and ALOX15B polymorphisms with psoriasis despite altered urinary excretion of 12(S)-hydroxyeicosatetraenoic acid. Br J Dermatol. 2015;172(2):337-344.

81. Alonso A, Julia A, Vinaixa M, et al. Urine metabolome profiling of immune-mediated inflammatory diseases. BMC Mede. 2016;14(1):133.

82. Kapoor SR, Filer A, Fitzpatrick MA, et al. Metabolic profiling predicts response to anti-tumor necrosis factor alpha therapy in patients with rheumatoid arthritis. Arthritis Rheum. 2013;65(6):1448-1456.

83. Haider AS, Cardinale IR, Whynot JA, Krueger JG. Effects of etanercept are distinct from infliximab in modulating proinflammatory genes in activated human leukocytes. J Invest Dermatol Symp Proc. 2007;12(1):9-15.

84. Kamaria M, Liao W, Koo JY. How long does the benefit of biologics last? An update on time to relapse and potential for rebound of biologic agents for psoriasis. Psoriasis Forum. 2010;16(2):36-42.

85. Papp K, Crowley J, Ortonne JP, et al. Adalimumab for moderate to severe chronic plaque psoriasis: efficacy and safety of retreatment and disease recurrence following withdrawal from therapy. Br J Dermatol. 2011;164(2):434-441.

86. Giraudeau P. Challenges and perspectives in quantitative NMR. Magn Reson Chem. Epub 2016 Jul 2.

87. Ritchie MD, Holzinger ER, Li R, Pendergrass SA, Kim D. Methods of integrating data to uncover genotype-phenotype interactions. Nat Rev Genetics. 2015;16(2):85-97.

88. Li S, Todor A, Luo R. Blood transcriptomics and metabolomics for personalized medicine. Comput Struct Biotechnol J. 2016;14:1-7.

89. Guo L, Milburn MV, Ryals JA, et al. Plasma metabolomic profiles enhance precision medicine for volunteers of normal health. Proc Natl Acad Sci U SA. 2015;112(35):E4901-E4910. 


\section{Supplementary material}

Table SI Medical subject headings terms used for literature search

\begin{tabular}{llll}
\hline Database & Search string & Filters & Yield \\
\hline PubMed & $((($ psoriasis OR “psoriatic arthritis”)) AND (Metabolomics OR metabolome OR & "Humans” species filter \\
& metabolites)) NOT Review (Publication Type) & "English” language filter \\
Embase & "psoriasis”/exp OR psoriasis OR “psoriatic arthritis”/exp OR “psoriatic arthritis” & Publication types: article \\
& AND (“metabolome”/exp OR metabolome OR "metabolomics”/exp OR & Quick limits: human, English only \\
& metabolomics OR metabolites) AND [humans]/lim AND [english]/lim NOT review:it) & \\
\hline
\end{tabular}

